Сиюхова А.M.

Адыгское этномузыковедение:

\title{
от истоков к международному признанию (к юбилею А. Н. Соколовой)
}

Аннотация: В статье представлен творческий портрет известного в России и за рубежом ученого-искусствоведа Аллы Николаевны Соколовой из Адыгеи, отмечающей в 2015 2. свой юбилей. Дается характеристика поликультурной среды в Казахстане, получение профессионального музыкального образования (Караганда, Алма-Ата), способствующего близкому знакомству с казахской музыкой и эффективными методиками проникновения в суть народного творчества. Описываются первые годы профессиональной деятельности и начало научного осмысления самобытности и ценности адыгской народной музыки. Приводится обоснование возможности и эффективности анализа этнической культуры ученъм, не являющимся генетическим носителем традиции. Подчеркивается, что этнографические исследования, которые начали проводить адыгские ученые, начиная с ХІХ века, основывались на традициях российской науки, и в значительной части излагались на русском языке. Основной метод анализа научной деятельности А. Н. Соколовой - диахронический - сочетается с методом структурного анализа, выделяющего основные натравления ее работы, такие как исследовательская деятельность, наставничество, просветительство, социальная практика. Новизна исследования заключается в том, что в статъе представлен краткий обзор основных трудов А. Н. Соколовой, в которьх сформироваласъ ее методология системного исследования адыгской музыкальной культуры. Доказывается, что ее научная и наставническая деятельность заложили основу научной школы. Работы А. Н. Соколовой стали примером для многих исследователей традиционной музыки народов Кавказа и России в целом. Раскрывается вопрос признания адыгского этномузыковедения в ее лице на международном уровне. Зарубежные выступления и публикации А. Н. Соколовой представляют перед международным научным сообществом музыкальную культуру адыгов системно, сочетая узко музыковедческую направленность с широким культурологическим освещением сущности сложнъхх процессов, протекающих в ней на протяжении длительного времени.

Ключевые слова: Этномузыковедение, А. Н. Соколова, юбилей, адыгская музыкальная культура, инструментальная музыка, системный метод, научная школ, последователи, социальные проекты, международное признание.

Review: The article presents a creative portrait of the famous in Russia and abroad scientist and art critic Alla Sokolova from Adygea. In 2015 Alla Sokolova is going to celebrate her anniversary. The author of the article provides a description of the polycultural environment in Kazakhstan and Sokolova's professional music education (received in Karaganda and Almaty) which encouraged a better understanding of Kazakh music and efficient methods of studying Kazakh folk art. The author also describes the first years of Alla Sokolova's professional activity and the beginning of scientific researches on the identity and values of the Adyghe folk music. The author of the present article proves the fact that it is possible to analyze and research ethnic culture for a scientist who is not a genetic bearer of tradition. It is emphasized that ethnographic researches started by Kazakhs in the nineteenth century were based on the traditions of Russian science and were written mostly in Russian. The main method used by the author to analyze the scientific activity of Alla Sokolova is the diachronic method combined with the method of structural analysis which has allowed to describe the main focus of her work including research, mentoring, enlightenment and social practice. The novelty of this research is caused by the fact that the author presents a brief review of the main works of Alla Sokolova that demonstrate how she developed the methodology of her system research of the Adyghe music culture. It is proved that her research and mentoring activities created the basis for a scientific school. Alla Sokolova's researches have become an example for many researchers of folk music of Caucasus and Russia in general. The author proves that Adyghe ethnomusicology presented by Alla Sokolova should be recognized at the international level. Foreign speeches and publications of Alla Sokolova present Adyghe music culture to the international academic community systematically. In her researches Alla Sokolova combines narrow music studies with a broader cultural research of long-term complex processes. 
Keywords: Alla Sokolova, anniversary, Adyghe music culture, instrumental music, system approach, scientific school, followers, ethnomusicology, social projects, international recognition.

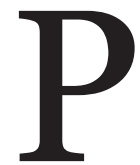
азвитие науки - объективный стремительно убыстряющийся процесс, при этом часто зависящий от множества субъективных факторов. Роль творческой личности в ряду таких факторов занимает одно из первых мест. Личность ученого способна дать новые направления научного поиска, раскрыть альтернативные возможности уже известных явлений природы и общества, изменить массовое мировоззрение. В нашей статье мы обратимся к вкладу в науку известного в России и за рубежом ученогоискусствоведа Аллы Николаевны Соколовой, отмечающей в 2015 г. свой юбилей. Ее исследования заметно укрепили и дали новый импульс развитию современного адыгского этномузыковедения, способствовали выходу научной информации об адыгской музыкальной культуре на международный уровень.

Во многом, тому, что А. Н. Соколова выбрала стезю этномузыковедения, способствовала культурная среда, в которой сформировалась личность ученого. Она родилась 7 июля 1955 года в многонациональном шахтерском городе Сарань Карагандинской области. По воспоминаниям Аллы Николаевны, по соседству с ее семьей проживали семьи немцев, чеченцев, болгар, евреев, в которых соблюдались национальные традиции и общение на родном языке. В то же время они были открыты к дружеским взаимоотношениям с соседями других национальностей. Таким образом, уже в детстве как будущий ученый она естественным образом получала и накапливала музыкальные, эстетические и общекультурные впечатления разного этнического содержания. Это сформировало открытость ее научного сознания ко всему новому, отличному от привычного русского уклада семейных и общественных отношений.

Профессиональное музыкальное образование А. Н. Соколова получила в Казахстане, входившем до 90-х годов XX века в состав СССР. В 1974 г. она с отличием закончила теоретическое отделение Карагандинского музыкального училища им. Таттимбета и сразу поступила на теоретико-композиторский факультет Алма-Атинской государственной консерватории. Алма-Атинская консерватория славилась очень сильной музыкальнотеоретической школой. В ее стенах работали

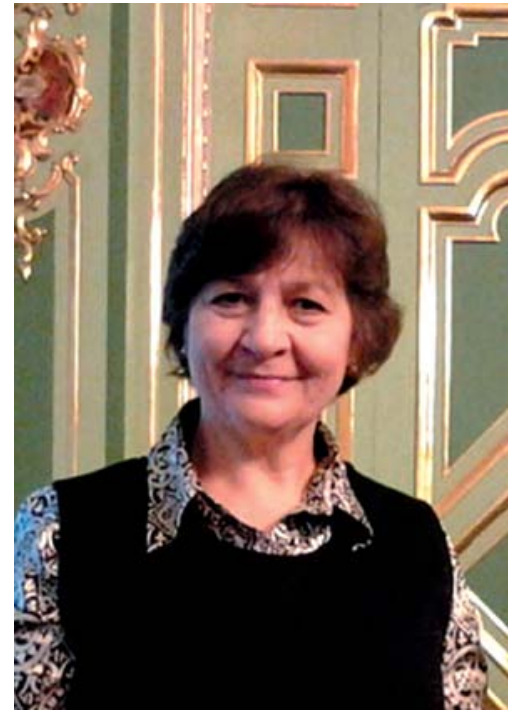

Рис. 1. Алла Николаевна Соколова, доктор искусствоведения, профессор, Заслуженный деятель искусств Республики Адыгея,

Заслуженный деятель науки Республики Адыгея, член Союза композиторов Республики Адыгея, профессор Института искусств Адыгейского государственного университета.

знаменитый соавтор бригадного «Учебника гармонии» И. Дубовский (И. Дубовский, С. Евсеев, И. Способин, В. Соколов), известные музыковеды и теоретики Петр Аравин, Варвара Дернова, Борис Ерзакович, Николай Тифтикиди и др. Среди педагогов студентки А. Н. Соколовой были Евгений Борисович Трембовельский, Витольд Давыдович Каменский, Людмила Викторовна Измайлова, Нина Ивановна Головнева. Помимо академического образования в сфере классической музыки, А. Н. Соколова по окончании консерватории получила ценный опыт знакомства с казахской музыкой и эффективными методиками проникновения в суть народного творчества.

Окончив консерваторию, молодой специалист поступает на работу в Майкопское музыкальное училище, впоследствии реорганизованное в Майкопское училище искусств им. У. Тхабисимова. Преподавая классические музыковедческие дисциплины - гармонию, полифонию, анализ музыкальных произведений, народное творчество, Алла Николаевна первая обратила внимание на отсутствие в образовательной программе училища, ра- 
ботающего в административном центре Адыгейской автономной области, дисциплины, связанной с адыгской традиционной музыкой. По ее инициативе данная дисциплина стала преподаваться, появилась возможность ежегодно выезжать в фольклорные экспедиции в аулы Адыгеи и Краснодарского края. Постепенно стал накапливаться научный и музыкальный материал по адыгскому этномузыковедению, с которым молодой преподаватель регулярно выступала на радио и страницах местной печати.

Интерес к целенаправленному научному анализу адыгской музыки пришел к А. Н. Соколовой отчасти случайно. Она откликнулась на просьбу Ш. Шу, уже тогда известного адыгского фольклориста, сделать нотные расшифровки народных инструментальных наигрышей. В начале 80-х гг. XX века в Адыгее не было специалистов-музыковедов, выходцев из адыгской этнической среды, способных выполнить эту работу. Следует заметить, что и сейчас таких специалистов единицы. Сложность работы, проделанной А. Н. Соколовой, заключалась в том, что при диатоническом строе и преобладании поступенности в мелодике, адыгские наигрыши имеют весьма замысловатую ритмическую структуру с обилием синкоп (смещений акцентов), отличаются импровизационностью, требующую высокого мастерства при нотной записи по слуху. Затратив на расшифровку десятка наигрышей определенное время, Алла Николаевна уловила системообразующие особенности их ладово-ритмической организации, закономерности развития музыкальной формы, а самое главное, прониклась любовью к этой музыке и осознанием ее эстетической ценности и самобытности. Это стало поводом для углубленного научного освоения уже с музыковедческих позиций инструментальной музыки адыгов.

Интерес исследователя к изучению традиционной адыгской музыки совпал с общим настроением в среде ученых этнографов и фольклористов. Стремительно разрушающиеся основания традиционного общества в XX веке подтолкнули когорту региональных исследователей к сбору и документальной фиксации остатков художественного наследия своего этноса. При этом адыгские фольклористы, как правило, более детально останавливались на традиции своего родного селения, так как обладали укорененными практическими знаниями и опытом в сфере народного творчества с детства. Научное сознание А. Н. Соколовой не было скованно территориально-локальными стереотипами в силу того, что она, вопервых, не являлась генетическим носителем традиции. Во-вторых, будучи преподавателем училища искусств, активный педагог организовала студенческие фольклорные экспедиции в районы Адыгеи, где проживали разные субэтнические сообщества адыгов - шапсуги, бжедуги, абадзехи и др., обладающие единым культурным ядром (язык, этический комплекс адыгэ хабзэ), но отличающимися в культурной периферии, в орбите которой находится и инструментальная музыка. Таким образом, сведения, полученные и научно освоенные исследователем, были шире и стали основанием для более глубоких обобщений по поводу адыгской музыкальной культуры как целостного явления.

Потребность в постоянном расширении своих познаний, в освоении чего-то нового, привели А. Н. Соколову к погружению в стихию адыгской музыкальной культуры. На первых порах ее исследовательская деятельность испытывала некоторый остракизм со стороны местного научного сообщества. Высказывалось мнение, что адекватное научное осмысление традиционной адыгской культуры, музыки в том числе, возможно лишь в случае, когда аналитик является ее генетическим носителем. Данный сковывающий фактор ученому удалось преодолеть через освоение адыгейского языка, разучивание старинных песен, возможностью исполнять отрывки наигрышей на адыгской скрипке (шычепщыне), выступлениями на адыгейском радио, слуховому познанию сотен инструментальных наигрышей. Действительно, мы до сих пор ничего бы не знали о самобытных культурах бушменов, пигмеев, маори и др., если бы ждали, пока появятся ученые - выходцы из этих этнических групп. Однако труды авторитетных европейских и североамериканских антропологов, этнологов и социологов (К. Леви-Стросс, Л. Уайт, Э. Тайлор и др.) дают нам вполне объективное представление о данных культурах. Если обернуться к истокам адыгской этнологии, то первыми бытописателями обычаев, традиций, народного искусства и религиозных представлений были европейские путешественники по Кавказу XIII-XIX столетий (Интериано, Тебу де Мариньи, Жан Батист Тавернье, Джеймс Белл, Джон Лонгворт и др.) и офицеры русской армии, проходившие службу на Кавказе во время Кавказской войны в XIX веке [1]. 
Следует также вспомнить знаменитую этнографическую экспедицию в Адыгею 30-х гг. XX века под руководством Г. М. Концевича, где в качестве переводчика выступал Ибрагим Цей - основоположник адыгейской литературы. В результате работы в 11-и аулах были собраны весьма ценные данные по культуре и быту адыгов, активно используемые в качестве эмпирического материала по настоящее время [2]. Самый ранний нотный сборник народных песен и инструментальных наигрышей адыгов, собранных Г. М. Концевичем и доработанный после его ареста А. Ф. Гребневым, был выпущен в 1941 году. Многотомное издание «Народные песни и инструментальные наигрыши адыгов» под редакцией Е. В. Гиппиуса стало издаваться с 1980 г. [3]. Этнографические исследования, которые начали проводить адыгские ученые, начиная с XIX века, основывались на традициях российской науки, и по большей части излагались на русском языке. Среди известных на Северном Кавказе ученых, оставивших значительный след в исследовании адыгской традиционной культуры стали Хан-Гирей, Адиль-Гирей Кешев, Шора Ногмов, Сафербий Сиюхов, Саральбий Мафедзев, Заур Налоев, Шабан Шу и др.

Однако к 80-м гг. XX века мировая и советская наука в области исследования культуры сделала громадный шаг вперед, определив новые перспективы научного поиска. Культурсоциологические теории М. Вебера и П. Сорокина, структурный функционализм Т. Парсонса, семиотическая концепция Ю. Лотмана, игровая теория И. Хейзинги, концепция сакрального Э. Дюркгейма с трудом завоевывали позиции в методологии этно-региональных научных исследований. Опять, как и сто лет назад, потребовался «свежий взгляд» со стороны, способный непредвзято, не преодолевая внутренних комплексов и стереотипов, выявить системные качества адыгской культуры поначалу в локальной сфере - музыке. По счастливому стечению обстоятельств такой «прививкой» новаторства в адыгском этномузыковедении стала научная деятельность А. Н. Соколовой.

Одной из первых работ Аллы Николаевны стала монография «Магомет Хагаудж и адыгская гармоника», изданная в Майкопе в 2000 г. Новаторский подход автора обусловил обращение к системно-этнофоническому методу, сформулированному наставником А. Н. Соколовой по диссертационной работе И. В. Ма- циевским - ведущим научным сотрудником Российского института истории искусств в Санкт-Петербурге. Суть данного метода выражается в неразрывности, синхронности изучения нескольких слагаемых: музыкального инструмента, музыки, на нем исполняемой, и музыкантов-исполнителей как выразителей этнического начала в контексте своей духовной культуры народа в диахронии ее исторического развития и современного состояния $[4$, c. 8]. Так, на примере жизни и творчества легендарного адыгского гармониста Магомета Хагауджа исследователь выявил глубинноисторические процессы, протекающие в культуре Адыгеи. Определяя причины укоренения гармоники в этносреде адыгов и закрепления ее значения как знака радости и веселья, А. Н. Соколова на основании изучения сложного исторического контекста делает заключение о том, что гармоника явилась способом сублимации внутренней потребности в празднике суровых кавказцев после длительной кровопролитной войны XIX века [4, с. 83].

Достойно уважения скрупулезность автора в сборе историко-этнографических данных, касающихся музыкального быта Северного Кавказа XIX-XX веков. Работа в архивах и фондах Ростова-на-Дону, Вятки, Москвы, Санкт-Петербурга и Лондона, экспедиционные поездки по аулам и станицам Адыгеи и Краснодарского края позволили найти множество интересных сведений об участии адыгских гармонистов в семейно-обрядной практике сел и коллективно-общественной жизни прикубанских городов - Екатеринодара, Армавира и др. Результатом изучения архивной документации становится реконструкция пути становления адыгской гармоники в качестве традиционного инструмента от использования готовых привозных гармоник из г. Вятки, через индивидуальные заказы вятским мастерам к формированию местного промысла инструментов в Краснодаре, Армавире и Майкопе, отвечающего эстетическим и эргономическим потребностям музыкантов. А. Н. Соколова также прослеживает изменения в самой конструкции гармоники в процессе приспособления ее к специфике народной адыгской культуры: максимальное облегчение массы инструмента и использование рояльной клавиатуры для игры «в слепую» стоя или в движении, изменение ладового строя (миксолидийский), использование нового декора, соответствующего кавказской эстетике. 
Глубокое проникновение в суть культурноисторических процессов и традиций этноса дают исследователю повод к формулированию важного вывода: обновление конструкции гармоники для органичного включения ее в традиционную музыкальную практику, в то же время ведут к мощному обновлению музыкального языка и жанрового состава [4, c. 82]. Новаторством А. Н. Соколовой становится тот факт, что она не ограничивается этнографическим описанием инструмента, истории его распространения, интонационным анализом наигрышей, но выводит исследование на уровень культурологического системного анализа. Гармоника в ее работе представляется концептом, совокупно содержащим логические, социально-исторические, эмоционально-психологические факторы осмысления музыкального орудия в качестве носителя этнической информации.

Подобное отношение к объекту исследования дало возможность А. Н. Соколовой рассмотреть гармонику в системе философских категорий времени и пространства, прошлого и будущего, традиций и новаций. Сравнивая ее с архаическими струнно-смычковыми и духовыми инструментами адыгов (шычепщын и камыль), исследователь определяет их символический смысл в этнокультуре: гармоника с ее большими выразительными возможностями, довольно сложной конструкцией символизировала яркое, новое, современное искусство, шычепщын и камыль становились символами исторического прошлого [4, с. 70]. Склонность к диалектическому постижению сути явлений привели А. Н. Соколову к осознанию полисемантичности гармоники, соотносящую ее как элемент культуры, как с прошлым, так и с будущим. Несмотря на то, что гармоника стала причиной уничтожения некоторых традиционных элементов культуры, она же выступила в качестве инструмента, позволяющего традиционной культуре сохраняться и развиваться [4, с. 71]. Звучание гармоники получило возможность магического воздействия на коллективное сознание этносоциума, тем самым превращая инструмент в носителя народного духовного знания и культуры [4, с. 84].

Достоверность описания звукомира адыгских гармошечных наигрышей сложилась при непосредственном прослушивании звукозаписей Хагауджа 1911-1913 гг., которые были обнаружены и перезаписаны А. Н. Соколовой во время работы в архивах корпорации EMI
(Лондон, Великобритания). На тот период (1999) А. Н. Соколова была первым исследователем из России, получившим разрешение на работу с документами фирмы «Граммофон».

Проникшись любовью к традиционной адыгской инструментальной музыке, А. Н. Соколова не могла обойти вниманием, помимо гармоники, инструмент, который придает особый колорит ансамблевому звучанию во время массовых празднеств. Речь идет о пхачиче - адыгских трещотках, ставшем объектом монографического исследования [5]. Автору, благодаря научному анализу этнографического материала, удается раскрыть идею того, что простота конструкции и способов игры на пхачиче, второстепенность в ткани общего звучания ансамбля, являются лишь внешним впечатлением, не отражающим глубину и сложность этого музыкального феномена. Помимо уточнения этнографических данных о строении инструмента, манерах исполнения, ареале распространения, ученый раскрывает глубинную полифункциональную сущность пхачича в этносознании и этнокультуре. Она находит в нем качества, позволяющие адыгским трещоткам органично включиться в мифологическую картину мира этноса, несмотря на то, что его повсеместное бытование в этносреде сформировалось сравнительно недавно. А. Н. Соколова приводит данные, собранные в фольклорных экспедициях, в которых, со слов информаторов, обнаруживается, что у бжедугов пхачичи появились приблизительно после Великой Отечественной войны.

Важным фактором укрепления традиции сопровождения музыкально-хореографического действа трещотками является способность их звучания формировать дополнительное звуковое пространство вокруг танцевального круга. «Звуки пхачича, - замечает А. Н. Соколова, - перекрывают звуки многолюдного празднества, они разносятся на большое расстояние, по ним определяют место проведения джегу (празднества, игрищ)» [5, с. 22]. Особенно рельефно функция звуковой границы праздника проявляется ночью, в отсутствие дневных шумов повседневной трудовой деятельности. Эти наблюдения дали основание исследователю раскрыть онтологические свойства инструмента как орудия магически оберегового свойства. "Апотропическая функция пхачича кроется в его «голосе», создающем ритуальный шум, - пишет А. Н. Соколова. - Пхачич - это голос чело- 
веческого мира, звуки природы, топота копыт...» [5, с. 23]. Олицетворяя собой мир человеческих звуков, пхачич не дает вторгнуться в праздник «нечеловеческому миру», выполняя тем самым функцию оберега для празднующего сообщества.

Магическая функция пхачича органично сплетается с театрально-зрелищной. Звуковая природа инструмента базируется не только на качестве материала, размере и пропорциях, но и на системе жестов, которая у пхачичао (исполнителя на трещотках) имеют особо выразительный характер [5, с. 52]. «Жесты пхачичао, - пишет А. Н. Соколова, - не просто ритмические жесты, они есть музыкальные и театральные жесты. Как музыкальные - они влияют на образно-смысловую драматургию наигрыша, а как театральные - создают новый план смыслов... через пластику движений пхачичао в определенной мере лицедействует - создает то игривые, то грациозно-величественные, то безудержно-веселые образы, вовлекая в них музыкантов, танцоров и, в конечном счете, всех присутствующих» [5, с. 53].

Включение пхачича в адыгскую культуру и его значительная и конструктивная модификация за столь короткий исторический период позволили А. Н. Соколовой назвать эти изменения феноменальными, символизирующими смену ценностно-эстетических идеалов, нашедших материальное воплощение в музыкальном орудии [5, с. 11]. По прошествии десятилетия после выхода книги эти мысли нами воспринимаются как привычные, само собой разумеющиеся. Однако следует признать, что для сущностного осмысления ритуально-магической и театрально-зрелищной функций пхачича в адыгской культуре исследования А. Н. Соколовой имели первостепенное значение.

Системный подход к изучению адыгской инструментальной музыки наиболее полно реализовался в монографии А. Н. Соколовой «Адыгская гармоника в контексте этнической музыкальной культуры» (2004 г.) [6]. Автор последовательно выстраивает модель изучаемого объекта, справедливо считая, что это необходимо для обеспечения конструктивной целостности на каждом этапе исследования по отношению к отдельным частям системы [6, с. 5]. Возможность и необходимость подобного научного метода базировались на признании высокого уровня развития адыгской традиционной музыкальной культуры. Экстраполируя философское определение целостности музыкального произведения как взаимообусловленности типа темы и типа формы [7], А. Н. Соколова рассматривает музыкальную культуру адыгов как фрактальную систему, где инструментальная культура представляется элементом целостной системы музыкальной культуры, отражающим все ее сущностные признаки [6, с. 10].

Способность взглянуть на адыгскую инструментальную музыку с философско-культурологических позиций привела А. Н. Соколову к осознанию онтологических свойств адыгской музыкальной культуры, позволяющих применить к ней понятие «адыгская музыкальная цивилизация» [6, с. 9]. В данное понятие ученый вкладывает совокупность качественных характеристик культуры, сформировавшей развитую систему музыкальных жанров и форм, распространённых и устойчиво функционирующих в широких пространственновременных границах проживания этнических адыгов (более чем в 50 странах мира). «Адыгская музыкальная цивилизация, - поясняет А. Н. Соколова, - формируется на основе единого образно-символического ряда, определяемого характерными ценностями и идеалами». В этом смысле музыкальная культура становится мощным фактором сохранения этнокультуры в условиях исторически обусловленной рассеянности этноса, существования в тесном иноэтническом окружении и разрушительного влияния глобализации [6, с. 12]. Ученый доказательно утверждает, что традиционный пласт музыкальной культуры, реализуемый посредством традиционного музыкального языка, несмотря ни на что, доминирует в этнической среде. Автор выявляет причины такой устойчивости в социокультурной, функциональной и семантической плоскостях бытования адыгской музыки, последовательно анализируемых в монографии [6, с. 17].

Важным аспектом деятельности А. Н. Cоколовой является наставничество - руководство научными исследованиями аспирантов и студентов (с 1999 г. преподает в Институте искусств Адыгейского государственного университета). По содержанию и качеству защищенных диссертаций под ее руководством можно утверждать, что она создала научную школу, т. к. во всех этих работах последовательно реализован предложенный ей принцип системности, вариативно применимый к разным уровням адыгской музыкальной культуры.

Первым исследованием в этом направлении стала диссертация автора настоящей 
статьи А. М. Сиюховой «Социокультурные аспекты музыкальной жизни адыгов», защищенная в 2001 г. в Государственном институте искусствознания (Москва) [8]. Во многом благодаря научному руководству А. Н. Соколовой удалось представить максимально обобщенную картину музыкальной культуры адыгов, не ограничивающейся только традиционной музыкой, но и полноправно включающую такие ее формы, как самодеятельность, фольклоризм, эстрадная и академическая музыка, а также становление профессионального музыкального образования в этносреде адыгов. Такой подход для того периода в гуманитарной науке был новаторским. Раньше в исследованиях музыкальной жизни этносообществ, как правило, делался акцент на народную музыку. Академическая музыка оценивалась как более значимая по отношению к народной, а эстрадная музыка этнических меньшинств СССР вовсе выпадала из исследовательского поля. Культурологическое осмысление музыкальной жизни адыгов как сложной системы дали основание для дальнейших изысканий автора в сфере духовной культуры этноса и реализовались в докторской диссертации «Концепт ночи в традиционной культуре адыгов» (2013) [9], при защите которой А. Н. Соколова выступила официальным оппонентом. В ходе обсуждения и рецензирования работы Алла Николаевна высказала ряд советов, которыми мы с научным консультантом профессором Государственного института искусствознания Е. В. Дуковым результативно воспользовались.

Системный этнофонический метод, примененный к исследованию адыгской музыки А. Н. Соколовой, органично был использован в диссертационном исследовании М. Ч. Анзароковой «Умар Тхабисимов в контексте адыгской музыкальной культуры», подготовленной под научным руководством А. Н. Соколовой и защищенной в Российском институте истории искусств (Санкт-Петербург) в 2006 г. [10]. Новаторским явился ракурс исследования, обусловивший осмысление сущности и роли творчества выдающегося музыканта Адыгеи второй половины XX века Умара Тхабисимова с ориентацией на культурно-исторический, социо-коммуникативный, этнопсихологический аспекты. Помимо скрупулезной аналитики музыкальных текстов композитора, были выявлены его внутренние творческие установки, бинарно направленные на «разрушение» и «созидание» адыгского фольклора в условиях жесткого прессинга советской идеологии. Глубина проникновения в тему обусловили обнаружение такого феномена в адыгской музыке XX века, как «переинтонирование», суть которого заключается в заимствовании песенных мелодий композитора народными музыкантами-гармонистами и превращение их в инструментальные танцевальные наигрыши, имеющие стилистику фольклорных образцов. Это становится возможным и органично вписывающимся в контекст традиционной музыкальной культуры благодаря танцевальным истокам песенного наследия У. Тхабисимова, которые исследователь обнаруживает, системно опираясь на культурно-исторические и музыкально-стилевые универсалии.

Преемницей научного метода А. Н. Соколовой стала Е. Л. Гогина, раскрывшая тему становления профессионального хорового искусства в Адыгее в диссертации 2008 г., защищенной в Ростовской консерватории [11]. Помимо обнаружения интонационно-стилистических истоков хоровых произведений адыгских композитов в адыгском фольклоре, автор системно выстраивает структуру хоровой культуры, взаимосвязанными элементами которой становятся композиторское творчество, исполнительство, формы концертномузыкальной практики, профессиональное музыкальное образование и пр. Также важным аспектом осмысления путей развития хоровой культуры стал анализ социокультурных условий ее формирования, во многом обусловленных культурной политикой государства и специфическими отношениями культуры и власти.

К представителям научной школы А. Н. Соколовой можно также в некоторой степени причислить исследователей адыгской народной музыки Ф. Ф. Хараеву и Л. А. Вишневскую. Несмотря на то, что они не являлись официальными аспирантом и докторантом Аллы Николаевны, в их работах прослеживается очевидная опора на научные разработки ученого, что явилось основанием обращения к ней с предложением стать официальным оппонентом на защитах диссертаций. Ф. Ф. Хараева в своем исследовании «Традиционные музыкальные инструменты и инструментальная музыка адыгов» (Музыкально-педагогический институт им. Гнесиных, 2000) признает, что «первым опытом комплексного исследования музыкального инструментария адыгов (затрагивающего вопросы форм 
и способов их функционирования, особенностей исполнительского искусства) являются работы А. Н. Соколовой. Некоторые музыкальные инструменты описаны ею впервые (упапшина - инструмент типа окарины, мажепшина - гребень). А. Н. Соколовой принадлежит и первая классификация адыгского инструментария в соответствии с систематикой Хорнбостеля-Закса» [12, с. 8]. Ф. Ф. Хараева расширяет ареал музыкального материала, привлекая музыкальные образцы, собранные в полевых экспедициях по Кабардино-Балкарии, Карачаево-Черкесии, Причерноморской Шапсугии, Моздокскому району Республики Северная Осетия и Урупскому району Краснодарского края. Также системный подход обусловил углубление культурологических вопросов, касающихся взаимосвязи музыкальных компонентов инструментальных текстов с хореографическими [12, с. 9].

В диссертационной работе Л. А. Вишневской «Северокавказское вокальное многоголосие: типология певческих моделей» (Саратовская государственная консерватория им. Л. В. Собинова, 2012) также заметно научное влияние метода А. Н. Соколовой. Наглядным свидетельством тому в тексте диссертации может служить количество ссылок на ее работы (около 20). В русле методик школы Л. А. Вишневская ставит и успешно решает задачи, которые она формулирует, как выявление характера исторических, природно-акустических и социокультурных предпосылок северокавказского вокального многоголосия; обоснование выразительных свойств музыки песнопений фонологическими (акустическими, артикуляторными, тембро-регистровыми, языково-речевыми) средствами вокализации; комплексная оценка семантического генезиса, синтаксического строения и композиционно-драматургической функции компонентов песенного многоголосия $[13$, c. 4]. Во введении к диссертации ученый отмечает, что по вопросам музыкальной диалектологии руководствуется положениями работ А. Н. Соколовой.

Пути системного исследования адыгской музыкальной культуры, намеченные в 90-е годы XX века А. Н. Соколовой, не исчерпали себя, т. к. остались еще не проанализированными на уровне диссертационных исследований такие весомые составляющие музыкальной жизни адыгов, как фольклоризм и новая городская песня. Однако реформы последнего десятилетия в образо- вании, к сожалению, затруднили приток молодежи в науку, уничтожив перспективу для большинства работать в системе специализированных СУЗов и вузов. При этом можно надеяться, что способность А. Н. Соколовой заражать собственным увлечением творческих людей, поможет самореализоваться бескорыстным талантливым молодым ученым в недалеком будущем. Но и в настоящем ученый умеет организовать вокруг себя известных в регионе и за его пределами специалистов, с которыми выполняются серьезные исследовательские проекты. Зачастую они социально значимы и актуальны для текущего времени и на перспективу. Речь идет о социологическом исследовании «Образовательная система в изучении традиционных культур полиэтничного города», проводимом вместе с Н. А. Нефляшевой и А. М. Сиюховой, этнокультурном проекте «Мой народ - моя родословная», где под руководством А. Н. Соколовой работали М. Ю. Унарокова, В. А. Гайко, нескольких долгосрочных исследовательских проектах, поддержанных Российским гуманитарным научным фондом и осуществляемых вместе с Т. П. Хлыниной, Г. Г. Тхагапсовой, А. Ю. Шадже, З. А. Жаде, Б. С. Хотко, М. А. Ешевым, А. Н. Шаповаленко и др.

Значимость научного вклада А. Н. Соколовой не ограничивается заслугами в разработке адыгской тематики. Ее работы стали примером для многих исследователей традиционной музыки народов Кавказа и России в целом. На ее труды ссылаются авторы, изучающие музыкальную культуру кавказских народов: Н. В. Чанба в работе, посвященной героической песне абхазов [14]; А. В. Гучева, кабардино-балкарский исследователь национальной гармоники [15]; 3. М. Кешева, пишущая о танцевальной культуре кабардинцев [16]; Д. М. Дзлиева, исследующая пляску в традиционной культуре осетин [17] и др. Универсальность метода, реализованного в трудах А. Н. Соколовой, обусловило обращение к нему не только кавказских исследователей, но и ученых, анализирующих традиционную музыкальную культуру других этнических сообществ, даже тех, где гармоника получила распространение намного раньше, чем у адыгов. На нее ссылаются И. М. Нуриева в диссертации, посвященной удмуртской музыкально-песенной традиции [18]; Р. Г. Буканова и Р. Ф. Мавлютов, пишущие о башкирском народном музыкальном искусстве [19] и пр. 
Не исключают из научного инструментария опыт А. Н. Соколовой и авторы - исследователи русской традиции в инструментальной и хореографической культуре: С. А. Москвичева при анализе традиционных гармошечных наигрышей тамбовского края [20]; А. А. Михайлова, занимающаяся анализом фольклорного инструментализма Поволжья на примере саратовской гармоники [21]; Д. С. Ковардеев и И. А. Корсакова, выявляющие многонациональные истоки танцевального искусства кубанского казачества [22]. Ссылают на А. Н. Соколову и авторы, разрабатывающие теорию этномузыковедения и этнокультурологии, такие как М. Ш. Абдулаева, рассматривающая вопросы этнокультурной идентичности народов Дагестана [23]; Ю. А. Поздняков в работе о методологических подходах исследования в отечественной науке феномена гармоники [24].

Научная пытливость А. Н. Соколовой сочетается в характере ученого с социальностью, под которой в данном случае нужно понимать стремление вовлечь в научное и музыкальное творчество множество единомышленников. С одной стороны, ее желанием было помочь талантливым народным музыкантам и молодым исследователям получить общественное признание, с другой стороны - обогатить культурную жизнь общества свежими музыкальными впечатлениями и новаторскими научными исследованиями. Именно для этого ученый организует концертные выступления традиционных адыгских музыкантов в Астрахани, Нальчике, Черкесске, Москве и Санкт-Петербурге, содействует звукозаписи талантливой адыгской молодежи на Би-би-си в Лондоне, устраивает ряд выступлений адыгских танцоров, певцов и гармонистов в Абердине и Эдинбурге (Шотландия).

Помимо очевидной пользы для самих музыкантов, эти выезды способствовали выходу адыгской традиционной музыки на международный уровень с получением высочайшей оценки и признания ее художественной ценности и самобытности. С докладами о традиционной культуре народов Кавказа А. Н. Соколова выступала в университетах Австрии, Венгрии, Германии, Грузии, Италии, Израиля, Казахстана, Китая, Литвы, Норвегии, Португалии, Турции, Шотландии, Чехии и других стран.

Продвижению научных сведений об адыгской музыке за рубеж также способствовали многочисленные публикации А. Н. Соколо- вой в иностранных изданиях. Вокальному полифоническому подголоску «жъыу», придающему адыгской инструментальной музыке особую выразительность, посвящена статья, опубликованная в Грузии [25]. Там же опубликована статья, культурологически раскрывающая смыслы и коды амебейного пения в адыгской традиционной культуре [26]. Две статьи размещены в турецких научных изданиях. В одной раскрываются вопросы традиционной адыгской музыки как фактора этнокультурных интеграционных процессов [27], вторая посвящена обстоятельствам появления и укрепления в адыгской культуре танца «Лезгинка» [28]. Аналитическая статья о трансформациях в инструментальной музыке адыгов в советскую эпоху и на постсоветском социокультурном пространстве Республики Адыгея опубликована в западноевропейском издании Lambert Academic Publishing (Германия) [29]. В статье, опубликованной в Китае, исследователь раскрывает феномен доминирования хореографии в социально-политической установке советской идеологии по отношению к развитию художественной культуры национальных меньшинств Советского Союза [30].

Сегодня не требует доказательства тот факт, что научная и педагогическая деятельность А. Н. Соколовой нашла должное признание за рубежом. Она является членом Европейского общества этномузыкологов и Британского форума этномузыкологов, представителем России в Международном сообществе по изучению музыкальных инструментов и инструментальной музыки. Зарубежные выступления и публикации А. Н. Соколовой представляют перед международным научным сообществом музыкальную культуру адыгов системно, сочетая узко музыковедческую направленность с широким культурологическим освещением сущности сложных процессов, протекающих в ней на протяжении длительного времени.

Подытоживая рассказ о роли А. Н. Соколовой в развитии современного адыгского этномузыковедения, мы не претендуем на беспристрастность, т. к. долгие годы сотрудничества обусловили уважительные товарищеские отношения. Однако пристрастность, смеем надеяться, не помешала объективности оценки громадного труда ученого, педагога, деятеля культуры. Ее вклад в науку и культуру по достоинству оценен государством: в 2004 г. ей 
присвоено звание заслуженного деятеля искусств Республики Адыгея, а в 2015 г. она получила звание заслуженного деятеля науки Республики Адыгея. Помимо высочайшего профессионализма, бесконечного трудолюбия, несомненного аналитического таланта, наиважнейшими качествами творческой личности исследователя стали открытость всему новому, стремление соответствовать самым высоким стандартам науки, смелость обращения к ведущим специалистам столичных городов с предложением сотрудничества. Так будучи молодым преподавателем, недавним выпускником консерватории, А. Н. Соколова написала письмо в Российский институт истории искусств (Санкт-Петербург) И. И. Земцовскому - признанному светилу в области фольклористики, и получила от него благожелательный ответ с приглашением приехать и показать свои материалы. Написав статью о смыслах и кодах амебейной формы песнопения в адыгской традиционной культуре (2010), А. Н. Соколова обратилась с просьбой о рецензии и содействии публикации к самому авторитетному специалисту по адыгской традиционной культуре 3. М. Налоеву. В ответном письме Заур Магометович с теплотой написал: «...во всех трех адыгских республиках Вы у нас одна такая талантливая и активная в области народного музыковедения, и все мы обожаем Вас. ... Да прибавится Вам еще сто лет счастливой творческой жизни» [31]. Считаем за огромную честь присоединиться к этому благопожеланию!

\section{Библиография:}

1. Адыги, балкарцы и карачаевцы в известиях европейских авторов XIII-XIX вв. Составление, редакция переводов, введение и вступительные статьи к текстам В. К. Гарданова. Нальчик: «Эльбрус», 1974. 636 с.

2. Религиозные пережитки у черкесов-шапсугов: Материалы шапсугской экспедиции 1939 г. М., 1940.82 с.

3. Народные песни и инструментальные наигрыши адыгов / Под ред Е. В. Гиппиуса. Т. 1. М.: Всесоюзное изд-во Советский композитор, 1980. 223 с.

4. Соколова А. Н. Магомет Хагаудж и адыгская гармоника. Майкоп: изд-во АГУ, 2000. С. 8.

5. Соколова А. Н. Пхачич - адыгские трещотки. Майкоп: Качество, 2002. 80 с.

6. Соколова А. Адыгская гармоника в контексте этнической музыкальной культуры. Майкоп: изд-во «Качество», 2004. 272 с.

7. Асафьев Б. Музыкальная форма как процесс. Л.: Музыка, 1971. 376 с.

8. Сиюхова А. М. Социокультурные аспекты музыкальной жизни адыгов. Дисс. ... кандидата культурологии. Москва, 2001. 168 с.

9. Сиюхова А. М. Концепт ночи в традиционной культре адыгов. Дисс. ... доктора культурологии. Москва, 2012. $377 \mathrm{c}$.

10. Анзарокова М. Ч. Умар Тхабисимов в контексте адыгской музыкальной культуры Дисс. ... кандидата искусствоведения. Санкт-Петербург, 2006. 238 с.

11. Гогина Е. Л. Становление профессионального хорового искусства в Адыгее. Дисс. ... кандидата искусствоведения. Ростов-на Дону, 2008. 241 с.

12. Хараева Ф. Ф. Традиционные музыкальные инструменты и инструментальная музыка адыгов. Дисс. ... кандидата искусствоведения. Москва, 2000. 417 с.

13. Вишневская Л. А. Северокавказское вокальное многоголосие. типология певческих моделей. Дисс. ... доктора искусствоведения. Саратов, 2012. 472 с.

14. Чанба Н. В. Героическая хоровая песня абхазов. Диссертация ... кандидата искусствоведения. Москва, 2014. $208 \mathrm{c}$.

15. Гучева А. В. Национальная гармоника Кабардино-Балкарии в аспекте межнациональных, музыкально-дидактических взаимодействий // Русская музыка в полиэтническом контексте. Материалы международной научной конференции. Министерство культуры Российской Федерации, Российский гуманитарный научный фонд, Казанская государственная консерватория (академия) им. Н.Г. Жиганова. Казань, 2012. С. 227-234.

16. Кешева 3. М. Танцевальная культура кабардинцев как источник формирования современного этнокультурного бренда // Культура и пространство. Тишков В.А., Малькова В.К. М., 2010. С. 154-175.

17. Дзлиева Д. М. Орнаментальные хороводы в традиционной хореографии осетин // Известия СОИГСИ. Школа молодых ученых. 2014. Т. 12. № 12. С. 239-252.

18. Нуриева И. М. Удмуртская музыкально-песенная традиция: специфика жанрообразования и функционирования. Дисс. ... доктора искусствоведения. Москва, 2015. 415 с. 
19. Буканова Р. Г., Мавлютова Р.Ф. Великая Отечественная война и развитие башкирского народного музыкального искусства // Научно-информационный журнал Армия и общество. 2010. № 2. С. 89-94.

20. Москвичева С. А. Традиционные гармошечные наигрыши тамбовского края («Канарейка»: особенности бытования) // Известия Самарского научного центра Российской академии наук. 2010. Т. 12. № 5-3. С. 855-859.

21. Михайлова А. А. Саратовская гармоника в социокультурном пространстве полиэтнического региона поволжья. Саратов: Саратовская государственная консерватория им. Л.В. Собинова, 2014. 408 с.

22. Ковардеев Д. С., Корсакова И.А. Многонациональные истоки танцевального искусства кубанского казачества // Музыка в информационном пространстве культуры третьего тысячелетия: проблемы, мнения, перспективы. Сборник научных трудов. М., 2014. С. 213-218.

23. Абдулаева М. Ш. Этнокультурная идентичность народов Дагестана: единство и многообразие. Диссертация ... доктора культурологии. Санкт-Петербург, 2013. 337 с.

24. Поздняков Ю. А. Гармоника в отечественной музыкальной науке: в поисках методологической парадигмы // Музыковедение. 2010. № 7. С. 50-55.

25. Sokolova A. Zhu - vocal part of Adyghe traditional instrumental polyphony // The Fourth International Symposium on Traditional Polyphony / Ed. By Rusudan Tzurtzumia, Joseph Jordania. -Tbilisi, 2010. P. $267-291$.

26. Sokolova A. The Meaning and Codes of the Amoebean Form of Singing in the Adyghe Traditional Culture // The Fifth International Symposium on Traditional Polyphony. 4-8 October 2010, Tbilisi, Georgia / International Research Center for Traditional Polyphony of Tbilisi Vano Sarajishvili. Tbilisi State Conservatoire, 2012. P. 123-132: notes.

27. Sokolova A. Traditional Adyghe music as Ethnointegrational Cultural Phenomenon // International symposium "Circassians in the 21-th Century: Problems and Opportunities. 22-25 September. - Ankara, 2011. P. 9.

28. Sokolova A. Circum Pontiac Lezginka Dance // 4-th Symposium of the ICTM Study Group on Music of the Turkic Speaking World. 18-20 April, 2014. Istanbul, Turkey. P. 38.

29. Sokolova A. Destructive, Constructive and Reconstructive processes in the Traditional Instrumental Music of the Adyghes during the Soviet and Post-Soviet times // Cultural paradigms and political change in the Caucasus. Ed. By Nino Tsitsishvili. Lambert Academic Publishing, Saarbrucken, 2010. P. 110-129.

30. Sokolova A. Domination of national dance of minorities as a result of cultural policy in the Soviet Union // 42nd World Conference of the International Council for Traditional Music, Shanghai, China, July 11 to 17 , 2013. P. 219-220.

31. Письмо 3. М. Налоева А. Н. Соколовой от 25.04.2010 года. Личный архив А. Н. Соколовой.

\section{References (transliterated):}

1. Sokolova A. N. Magomet Khagaudzh i adygskaya garmonika. Maikop: izd-vo AGU, 2000. S. 8.

2. Sokolova A. N. Pkhachich - adygskie treshchotki. Maikop: Kachestvo, 2002. 80 s.

3. Sokolova A. Adygskaya garmonika v kontekste etnicheskoi muzykal'noi kul'tury. Maikop: izd-vo «Kachestvo», 2004. 272 s.

4. Asaf'ev B. Muzykal'naya forma kak protsess. L.: Muzyka, 1971. 376 s.

5. Siyukhova A. M. Sotsiokul'turnye aspekty muzykal'noi zhizni adygov. Diss. ... kandidata kul'turologii. Moskva, 2001. 168 s.

6. Siyukhova A. M. Kontsept nochi v traditsionnoi kul'tre adygov. Diss. ... doktora kul'turologii. Moskva, 2012. $377 \mathrm{~s}$.

7. Anzarokova M. Ch. Umar Tkhabisimov v kontekste adygskoi muzykal'noi kul'tury Diss. ... kandidata iskusstvovedeniya. Sankt-Peterburg, 2006. 238 s.

8. Gogina E. L. Stanovlenie professional'nogo khorovogo iskusstva v Adygee. Diss. ... kandidata iskusstvovedeniya. Rostov-na Donu, 2008. 241 s.

9. Kharaeva F. F. Traditsionnye muzykal'nye instrumenty i instrumental'naya muzyka adygov. Diss. ... kandidata iskusstvovedeniya. Moskva, 2000. 417 s.

10. Vishnevskaya L. A. Severokavkazskoe vokal'noe mnogogolosie. tipologiya pevcheskikh modelei. Diss. ... doktora iskusstvovedeniya. Saratov, 2012. $472 \mathrm{~s}$.

11. Chanba N. V. Geroicheskaya khorovaya pesnya abkhazov. Dissertatsiya ... kandidata iskusstvovedeniya. Moskva, 2014. $208 \mathrm{~s}$.

12. Gucheva A. V. Natsional'naya garmonika Kabardino-Balkarii v aspekte mezhnatsional'nykh, muzykal'no-didakticheskikh vzaimodeistvii // Russkaya muzyka v polietnicheskom kontekste. Materialy mezhdunarodnoi nauch- 
noi konferentsii. Ministerstvo kul'tury Rossiiskoi Federatsii, Rossiiskii gumanitarnyi nauchnyi fond, Kazanskaya gosudarstvennaya konservatoriya (akademiya) im. N.G. Zhiganova. Kazan’, 2012. S. 227-234.

13. Kesheva Z. M. Tantseval'naya kul'tura kabardintsev kak istochnik formirovaniya sovremennogo etnokul'turnogo brenda // Kul'tura i prostranstvo. Tishkov V.A., Mal'kova V.K. M., 2010. S. 154-175.

14. Dzlieva D. M. Ornamental'nye khorovody v traditsionnoi khoreografii osetin // Izvestiya SOIGSI. Shkola molodykh uchenykh. 2014. T. 12. № 12. S. 239-252.

15. Nurieva I. M. Udmurtskaya muzykal'no-pesennaya traditsiya: spetsifika zhanroobrazovaniya i funktsionirovaniya. Diss. ... doktora iskusstvovedeniya. Moskva, 2015. $415 \mathrm{~s}$.

16. Bukanova R. G., Mavlyutova R.F. Velikaya Otechestvennaya voina i razvitie bashkirskogo narodnogo muzykal'nogo iskusstva // Nauchno-informatsionnyi zhurnal Armiya i obshchestvo. 2010. № 2. S. 89-94.

17. Moskvicheva S. A. Traditsionnye garmoshechnye naigryshi tambovskogo kraya («Kanareika»: osobennosti bytovaniya) // Izvestiya Samarskogo nauchnogo tsentra Rossiiskoi akademii nauk. 2010. T. 12. № 5-3. S. 855-859.

18. Mikhailova A. A. Saratovskaya garmonika v sotsiokul'turnom prostranstve polietnicheskogo regiona povolzh'ya. Saratov: Saratovskaya gosudarstvennaya konservatoriya im. L.V. Sobinova, 2014. 408 s.

19. Kovardeev D. S., Korsakova I.A. Mnogonatsional'nye istoki tantseval'nogo iskusstva kubanskogo kazachestva // Muzyka v informatsionnom prostranstve kul'tury tret'ego tysyacheletiya: problemy, mneniya, perspektivy. Sbornik nauchnykh trudov. M., 2014. S. 213-218.

20. Abdulaeva M. Sh. Etnokul'turnaya identichnost' narodov Dagestana: edinstvo i mnogoobrazie. Dissertatsiya ... doktora kul'turologii. Sankt-Peterburg, 2013.337 s.

21. Pozdnyakov Yu. A. Garmonika v otechestvennoi muzykal'noi nauke: v poiskakh metodologicheskoi paradigmy // Muzykovedenie. 2010. № 7. S. 50-55.

22. Sokolova A. Zhu - vocal part of Adyghe traditional instrumental polyphony // The Fourth International Symposium on Traditional Polyphony / Ed. By Rusudan Tzurtzumia, Joseph Jordania. -Tbilisi, 2010. P. 267-291.

23. Sokolova A. The Meaning and Codes of the Amoebean Form of Singing in the Adyghe Traditional Culture // The Fifth International Symposium on Traditional Polyphony. 4-8 October 2010, Tbilisi, Georgia / International Research Center for Traditional Polyphony of Tbilisi Vano Sarajishvili. Tbilisi State Conservatoire, 2012. P. 123132: notes.

24. Sokolova A. Traditional Adyghe music as Ethnointegrational Cultural Phenomenon // International symposium "Circassians in the 21-th Century: Problems and Opportunities. 22-25 September. - Ankara, 2011. P. 9.

25. Sokolova A. Sircum Pontiac Lezginka Dance // 4-th Symposium of the ICTM Study Group on Music of the Turkic Speaking World. 18-20 April, 2014. Istanbul, Turkey. P. 38.

26. Sokolova A. Destructive, Constructive and Reconstructive processes in the Traditional Instrumental Music of the Adyghes during the Soviet and Post-Soviet times // Cultural paradigms and political change in the Caucasus. Ed. By Nino Tsitsishvili. Lambert Academic Publishing, Saarbrucken, 2010. P. 110-129.

27. Sokolova A. Domination of national dance of minorities as a result of cultural policy in the Soviet Union // 42nd World Conference of the International Council for Traditional Music, Shanghai, China, July 11 to 17, 2013. P. 219-220.

28. Pis'mo Z. M. Naloeva A. N. Sokolovoi ot 25.04.2010 goda. Lichnyi arkhiv A. N. Sokolovoi. 